ORIGINAL ARTICLE

\title{
Is Platelet Rich Plasma (PRP) Injection in Sternotomy Wound Better for Healing and Pain Control?
}

\author{
${ }^{(1)}$ Mohamed I. Alanwar, ${ }^{(2)}$ Mohamed M. Allam, ${ }^{(3)}$ Khaled M. Helmy \\ ${ }^{(1)}$ Cardiothoracic Surgery Department, Faculty of Medicine, Zagazig University, Zagazig , Egypt. \\ (2) Cardiology Department, Faculty of Medicine, Zagazig University, Zagazig, Egypt. \\ ${ }^{(3)}$ Department of Anesthesia and Surgical Intensive Care, Faculty of Medicine - Zagazig University, \\ Zagazig , Egypt.
}

\section{Corresponding Author:Name: Mohamed Ibrahim Alanwar Email: \\ anwar7666@yahoo.com}

$\begin{array}{ll}\text { Submit Date } & \text { 2020-04-01 } \\ \text { Revise Date } & 2020-04-13 \\ \text { Accept Date } & 2020-04-13\end{array}$

\section{INTRODUCTION}

O ne of the most severe complications associated with cardiovascular surgery is sternal wound infection (SWI). It is related to an increase in the hospitalization duration, hospital costs and the need for surgical reintervention [1].

A clinical preventive approach has not yet been clearly established. The topical application of autologous platelet rich plasma (PRP) has been identified to promote earlier wound healing in a variety of settings [2].

PRP application is used to speed up the healing cascade through the action of elevated

\section{ABSTRACT}

Background: Post-cardiac surgery with superficial and deep sternal wound infections (SWI \& DSWI) raises morbidity and stay at hospital. In other surgical settings, autologous platelet-rich plasma (PRP), extracted from the patient's own blood, was used to facilitate effective wound healing. The aim of this work was to evaluate the usefulness of Platelet Rich Plasma (PRP) injection in sternotomy wound of patients undergoing cardiac surgical procedures. Patient and methods: A prospective study for patients underwent open heart surgery from June 2013 until June 2016 at Zagazig University. One hundred sixty patients were divided into two groups; group A: there is application of PRP before and after sternal closure in about 80 patients and group B: Sternotomy closure by ordinary manner without application of PRP in 80 patients. Results: Mean age was $54.32 \pm 8.005$ in group (A), ranged from 30 to 72 years and in group B, mean age was 55.21 \pm 9.06 , ranged from 28 to 70 years. Follow-up of postoperative SSWI and DWSI showed that the use of PRP had no adverse reactions in our study. Also, the incidence of superficial and deep sternal wound infection from one month to more than 3 months in group A was reduced. Postoperative pain in group A had a significantly low incidence of moderate and severe pain in the period from one month to more than 3 months. Conclusion: Application of PRP in sternotomy wound in the treatment community was found to be quick, safe and significantly ced postoperative infection levels and pain severity. sternal wound infections 


\section{AIM OF THIS WORK}

The aim of this study was to evaluate the usefulness of Platelet Rich Plasma (PRP) injection in sternotomy wound of patients undergoing cardiac surgical procedures.

\section{PATIENTS AND METHODS}

Prospective study for patients underwent open heart surgery from June 2013 until June 2016 at Zagazig University. We selected about 160 patients; divided into two groups: Group A: There is application of PRP before and after sternal closure in about 80 patients. Group B: Sternotomy closure by ordinary manner without application of PRP in 80 patients.

Preoperative preparation: All patients must stop antiplatelet for at least 5 days and not take any anti-inflammatory preparation. Exclusion criteria: Long bypass time $>120$ minutes, renal or hepatic impairment, combined surgeries, HbA1c > 8, delayed sternal closure, pediatric patients, bleeding, emergency operation and low EF patients.

Written informed consent was obtained from all participants, the study was approved by the research ethical committee of Faculty of Medicine, Zagazig University. The study was done according to The Code of Ethics of the World Medical Association (Declaration of Helsinki) for studies involving humans.

\section{Platelet rich plasma (PRP) preparation:}

For preparation about $10 \mathrm{~cm}$ of PRP: Firstly, we drew about $100 \mathrm{~cm}$ blood from CVP after induction for anaesthesia. The drawn blood was put in sterile patient vacutainer (which contained sodium citrate which is an anticoagulant that does not affect in platelets).we used 50 sterile patient vaccination tube(each tube accommodates about $2 \mathrm{~cm}$ blood). Then, we started centrifuge 1500 round PM for 15 minutes. The content of tube was divided into 3 layers: basal layer: RBCs, mid layer: buffy coat, and upper layer: Plasma supernatant. By large bore cannulation, upper and mid layers of fluid were taken in the tube and put in plain vacutainer tube, then centrifuged for 5 minimal with $3500 \mathrm{rpm}$. It formed 2 layers; upper layer of plasma and basal layer of platelets. About $2 / 3$ of plasma layer was removed. Remnant of plasma layer and platelet layer were mixed to form PRP. We prepared about $10 \mathrm{~cm}$ PRP which was applied at sternal closed edges after closure, the sterum by wires and at site of jenter and exit the sternal exit.

\section{Preoperative and intraoperative management:}

All patients were prepared preoperatively in same manner. Firstly shaved on the night before operation. Then after induction of general anaesthesia and blood drawn for PRP preparation, the patients were draped and the skin was covered with adhesive plastic sheet. Standard full median stenrotomy and extracorporeal circulation were performed for all patients. Heparin was administered to achieve Act level over 500 second, at dosage of $300 \mathrm{Iu} / \mathrm{kg}$. Systemic temperature left to be draft to around 32 degree. Intermittent antegrade warm cardioplegia of the blood is in all cases. Rewarming and weaning from CBP were performed after complete the surgery, then protamine were started to completely reverse heparin. Sternal closure was performed with eight stainless steel wires and then covered by two layers of reabsorbable suture to the muscle and subcutaneous tissues. Monocryl 3/0 was closed to skin.

\section{Postoperative management:}

\section{Diagnosis of deep sternal wound infection:}

DSWI diagnosis occurs when patients meet one or more of the following conditions, according to the Centers for Disease Control and Prevention Guideline [6]: An organism is removed from the culture of mediastinal tissue or fluid. During sternal reoperation evidences of mediastinitis are seen. Either of the following is present: chest pain, sternal instability, temperature above $38^{\circ} \mathrm{C}$ and either a purulent discharge from the mediastinum or an organism isolated from the blood culture or drainage culture of the mediastinal region [6].

SSWI are both skin and subcutaneous tissue infections only and sternum still healthy, require routine regular wound dressing, followed by antibiotic therapy and/or VAC and/or wire removal [6].

Degree of sternotomy pain: 
We assessed the degree of pain based on Visual Analog Scale (VAS). VAS is a measure of psychometric response that can be used in questionnaires. This is a measuring device not specifically measured for individual characteristics or attitudes. When responding to a VAS object, respondents indicate their degree of agreement to a statement by indicating a location between two endpoints along a continuous line. The continuous or equivalent dimension of the scale separates it from discrete scales such as the Likert scale. There is proof that the visual scale has superior metric properties than the discrete scales [7].

All patients were transfer to ICU. Analgesic given in both group was opioid according to need for first 5 days postoperatively. In case of signs of wound infections, wound dressing was done regularly. Microbiological samples were sent. Degree of pain was detected in both groups. It was classified into minor (very mild, discomforting, and tolerable), moderate (distressing, very distressing, and intense), severe (very intense, utterly horrible, excruciating unbearable, unimaginable unspeakable).

Postoperative antibiotic prophylaxis is same in both groups for 7 days postoperatively. Usually patients were discharged after 7 days postoperatively with oral antibiotics. In case of isolation of organism from wound infection, antibiotic is given according to the culture. Postoperatively all patients were followed up in outpatient clinic at one week, one month and 3 months.

\section{Statistical analysis}

The SPSS software for Windows, version 23 (SPSS Inc., Chicago, IL) was used for the statistical analysis. Continuous variables are presented as mean \pm standard deviation and as absolute numbers or percentages are described as categorical variables. Prior to statistical analysis the data were tested for normality. The univariate analysis $t$-test was used to evaluate normally distributed continuous variables, while the Mann Whitney U-test was used for those variables that were not normally distributed. Follow-up events that occur over time were defined using the technique of the Kaplan Meier survival curve and associated tests of significance for the log rating. Comparisons where $\mathrm{P}<0.05$ is considered important.

\section{RESULTS}

Tables 1, showed that mean age was $54.32 \pm 8.005$ in group (A), ranged from 30 to 72 years and male to female ratio of $48: 32$. In group $\mathrm{B}$, mean age was 55.21 \pm 9.06 , ranged from 28 to 70 years, with male to female ratio of 45:35. The two classes were homogeneous for pre-operative and intraoperative risk factors, with no major statistical variations.

Table 2, Follow-up of postoperative sternal wound infection showed that PRP had no adverse reactions in our study and reduced the incidence of superficial sternal wound infection from one month to more than 3 months in group A. On the other hand, superficial sternal wound infection increased significantly in group B. Postoperative deep sternal wound infection was reduced with PRP from one week to more than 3 months in group A but in group B increased significantly. The hospital readmission rate for re-intervention (need VAC, secondary suture, pectoralis flap or omental flap) increased significantly postoperatively till the end of follow-up period in group B.

Table 3, Cultures of infected sternal wound showed that microorganisms associated with SWI and DSWI were mostly Staphylococcus strains.

Table 4, Regarding degree of pain depending on Visual Analogue Scale (VAS), follow-up of postoperative pain showed that the use of PRP significantly reduced the incidence of moderate and severe pain in the period from one month to more than 3 months in group A. on the other hand minor pain was the more prevalent degree in group A after one week to more than 3 months of follow-up period.

Table 5, Over the follow-up period from one week postoperative to more than 3 months, survival curves showed that patients in group A had less frequency of superficial (Figure 1) and deep sternal wound infections (Figure 2) significantly compared to group B ( $\log$ Rank $\mathrm{p}=0.013$ and 0.047 respectively). 
Table (1): Preoperative demographic, risk factors, intraoperative and postoperative risk factors in both groups

\begin{tabular}{|c|c|c|c|}
\hline Parameters & $\begin{array}{l}\text { Group A } \\
n=80\end{array}$ & $\begin{array}{l}\text { Group B } \\
n=80\end{array}$ & P-value \\
\hline $\begin{array}{l}\quad \text { Age Mean } \pm \text { SD } \\
\text { Gender ( male) } \\
\text { BMI>30 } \\
\text { Smoking } \\
\text { Dyslipidemia } \\
\text { DM } \\
\text { Hypertension } \\
\text { Chronic heart failure } \\
\text { History of endocarditis } \\
\text { COPD } \\
\text { History of CKD } \\
\text { History of steroids }\end{array}$ & $\begin{array}{l}54.32 \pm 8.005 \\
48(60 \%) \\
5(6.3 \%) \\
52(65 \%) \\
31(38.3 \%) \\
51(63.8 \%) \\
41(63.1 \%) \\
8(10 \%) \\
3(3.8 \%) \\
7(8.8 \%) \\
4(5 \%) \\
2(2.5 \%)\end{array}$ & $\begin{array}{l}55.21 \pm 9.06 \\
45(56.25 \%) \\
6(7.5 \%) \\
56(70 \%) \\
33(41.3 \%) \\
48(60 \%) \\
45(56.3 \%) \\
12(15 \%) \\
4(5 \%) \\
6(7.5 \%) \\
5(6.3 \%) \\
3(3.8 \%)\end{array}$ & $\begin{array}{l}0.51 \\
0.73 \\
0.75 \\
0.50 \\
0.74 \\
0.63 \\
0.33 \\
0.34 \\
0.69 \\
0.66 \\
0.73 \\
0.65\end{array}$ \\
\hline $\begin{array}{l}\text { Caradiac function } \\
\text { EF \% Mean } \pm \text { SD } \\
\text { Albumin (g/dl) Mean } \pm \text { SD } \\
\text { Haemoglobin (g/dl) Mean } \pm \text { SD } \\
\text { TLC at admission Mean } \pm \text { SD } \\
\text { Platelets Mean } \pm \text { SD }\end{array}$ & $\begin{array}{l}52.06 \pm 8.35 \\
4.06 \pm 0.53 \\
11.72 \pm 2.04 \\
7.57 \pm 2.39 \\
190.82 \pm 56.11\end{array}$ & $\begin{array}{l}51.41 \pm 6.14 \\
3.97 \pm 0.39 \\
11.36 \pm 3.19 \\
7.45 \pm 1.97 \\
189.03 \pm 59.68\end{array}$ & $\begin{array}{l}0.57 \\
0.28 \\
0.057 \\
0.72 \\
0.83\end{array}$ \\
\hline $\begin{array}{c}\text { Opeation status } \\
\text { Elective } \\
\text { Non-elective }\end{array}$ & $\begin{array}{l}69(86.3 \%) \\
11(13.8 \%)\end{array}$ & $\begin{array}{l}71(88.8 \%) \\
9(11.3 \%)\end{array}$ & 0.63 \\
\hline $\begin{array}{l}\text { Total length of stay (days) } \\
\text { Mean } \pm \text { SD }\end{array}$ & $10.37 \pm 2.21$ & $10.15 \pm 2.27$ & 0.75 \\
\hline \multicolumn{4}{|c|}{ Intraoperative and postoperative risk factors } \\
\hline Isolated CABG with LIMA & $46(57.5 \%)$ & $52(65.0 \%)$ & 0.33 \\
\hline Isolated valvular lesion & $30(37.5 \%)$ & $25(31.25 \%)$ & 0.32 \\
\hline CABG + Valves & $4(5 \%)$ & $3(3.75 \%)$ & 0.69 \\
\hline $\begin{array}{l}\text { Cardiopulmonary bypass time } \\
\text { (CPB)>60minutes }\end{array}$ & $12(15 \%)$ & $13(16.3)$ & 0.82 \\
\hline On-Pump (CPB) & $60(75 \%)$ & $65(70 \%)$ & 0.47 \\
\hline $\begin{array}{l}\text { Operative time (incision to } \\
\text { closure)>300 minutes }\end{array}$ & $14(17.5 \%)$ & $12(15 \%)$ & 0.66 \\
\hline Acute renal failure & $3(3.8 \%)$ & $5(6.3 \%)$ & 0.46 \\
\hline Postoperative delirium & $6(7.5 \%)$ & $3(3.8 \%)$ & 0.30 \\
\hline Respiratory failure & $3(3.8 \%)$ & $1(1.3 \%)$ & 0.31 \\
\hline Hospital mortality & $6(7.5 \%)$ & $5(6.3 \%)$ & 0.75 \\
\hline
\end{tabular}

DM- diabetes mellitus; COPD - chronic obstructive pulmonary disease; CKD - chronic kidney disease; $\mathrm{EF}$ - ejection fraction; BMI - body mass index; CPB; cardiopulmonary bypass. TLC- total leucocytic count

CABG, coronary artery bypass graft; IMA, internal mammary artery, CPB; cardiopulmonary bypass 
Table (2): Postoperative sternal wound infection

\begin{tabular}{|c|c|c|c|}
\hline & $\begin{array}{l}\text { Group A } \\
\mathrm{n}=74\end{array}$ & $\begin{array}{l}\text { Group B } \\
\mathrm{n}=75\end{array}$ & $\mathrm{P}$-value \\
\hline $\begin{array}{l}\text { After one week } \\
\text { Superficial wound infection } \\
\text { Deep wound infection } \\
\text { Patients need secondary suture }\end{array}$ & $\begin{array}{l}3(4.10 \%) \\
- \\
-\end{array}$ & $\begin{array}{l}6(8 \%) \\
4(5.30 \%) \\
3(4 \%)\end{array}$ & $\begin{array}{l}0.31 \\
0.044 \\
0.038\end{array}$ \\
\hline $\begin{array}{l}\text { After one month } \\
\text { Superficial wound infection } \\
\text { Deep sternal wound infection } \\
\text { Patients need VAC } \\
\text { Patients need secondary suture } \\
\text { Patients need pectoralis flap } \\
\text { Patients need omental flap }\end{array}$ & $\begin{array}{l}1(1.4 \%) \\
1(1.4 \%) \\
1(1.4 \%) \\
1(1.4 \%) \\
0 \\
0\end{array}$ & $\begin{array}{l}12(16 \%) \\
8(10.7 \%) \\
6(8 \%) \\
1(1.33 \%) \\
0 \\
0\end{array}$ & $\begin{array}{l}0.002 \\
0.017 \\
0.057 \\
0.99 \\
- \\
-\end{array}$ \\
\hline $\begin{array}{l}\text { After } 3 \text { months } \\
\text { Superficial wound infection } \\
\text { Deep sternal wound infection } \\
\text { Patients need V A C } \\
\text { Patients need secondary suture } \\
\text { Patients need pectoralis flap } \\
\text { Patients need omental flap }\end{array}$ & $\begin{array}{l}0 \\
0 \\
0 \\
0 \\
0 \\
0\end{array}$ & $\begin{array}{l}3(4 \%) \\
5(6.7 \%) \\
3(4 \%) \\
4(5.30 \%) \\
1(1.33 \%) \\
5(6.7 \%)\end{array}$ & $\begin{array}{l}0.002 \\
0.024 \\
0.08 \\
0.045 \\
0.32 \\
0.025\end{array}$ \\
\hline
\end{tabular}

Vacuum-assisted closure (VAC)

Table (3): Microorganisms associated with SWI and DSWI

\begin{tabular}{l|l} 
Microorganisms & $\mathbf{n = 4 0}(\mathbf{\%})$ \\
\hline Coagulase-negative Staphylococcus & $18(45 \%)$ \\
Staphylococcus aureus (MSRA) & $5(12.5 \%)$ \\
Klebsiella pneumoniae & $4(10 \%)$ \\
Escherichia coli & $5(12.5 \%)$ \\
Enterococcus faecalis & $3(7.5 \%)$ \\
Enterobacter aerogenes & $1(2.5 \%)$ \\
Enterococcus ssp & $1(2.5 \%)$ \\
Pseudomonas aeruginosa & $2(5 \%)$ \\
Acinetobacter ssp & $1(2.5 \%)$
\end{tabular}


Table (4): Degree of sternotomy pain

\begin{tabular}{|c|c|c|c|}
\hline & $\begin{array}{l}\text { Group A } \\
\mathrm{n}=74\end{array}$ & $\begin{array}{l}\text { Group B } \\
n=75\end{array}$ & P-value \\
\hline $\begin{array}{l}\text { After } 1 \text { week } \\
\text { minor pain } \\
\text { moderate pain } \\
\text { severe pain }\end{array}$ & $\begin{array}{l}54(73 \%) \\
20(27 \%) \\
-\end{array}$ & $\begin{array}{l}10(13.3 \%) \\
45(60 \%) \\
20(26.7 \%)\end{array}$ & $\begin{array}{l}<0.001 \\
<0.001 \\
0.001\end{array}$ \\
\hline $\begin{array}{l}\text { After 1month } \\
\text { no pain } \\
\text { minor pain } \\
\text { moderate } \\
\text { severe pain }\end{array}$ & $\begin{array}{l}20(27 \%) \\
48(64.8 \%) \\
5(6.8 \%) \\
1(1.4 \%)\end{array}$ & $\begin{array}{l}0 \\
22(29.40 \%) \\
34(45.30 \%) \\
19(25.30 \%)\end{array}$ & $\begin{array}{l}0.012 \\
0.011 \\
0.002 \\
0.004\end{array}$ \\
\hline $\begin{array}{l}\text { After 3month } \\
\text { no pain } \\
\text { minor pain } \\
\text { moderate } \\
\text { severe pain }\end{array}$ & $\begin{array}{l}55(74.3 \%) \\
12(16.2 \%) \\
5(6.8 \%) \\
1(1.4 \%)\end{array}$ & $\begin{array}{l}9(12 \%) \\
40(53.30 \%) \\
15(20 \%) \\
11(14.7 \%)\end{array}$ & $\begin{array}{l}0.023 \\
0.016 \\
0.030 \\
0.002\end{array}$ \\
\hline
\end{tabular}

Table (5): Survival functions for superficial sternal and deep wound infections in both groups

\section{\begin{tabular}{l|l} 
Chi-Square & P-value
\end{tabular}}

\section{Superficial sternal infection}

\begin{tabular}{|l|l|l|}
\hline Log Rank & 6.219 & 0.013 \\
\hline Breslow (Generalized Wilcoxon) & 5.066 & 0.024 \\
\hline Tarone-Ware & 5.621 & 0.018 \\
\hline deep sternal infection & & 0.047 \\
\hline Log Rank & 3.928 & 0.051 \\
\hline Breslow (Generalized Wilcoxon) & 4.02 & 0.049
\end{tabular}

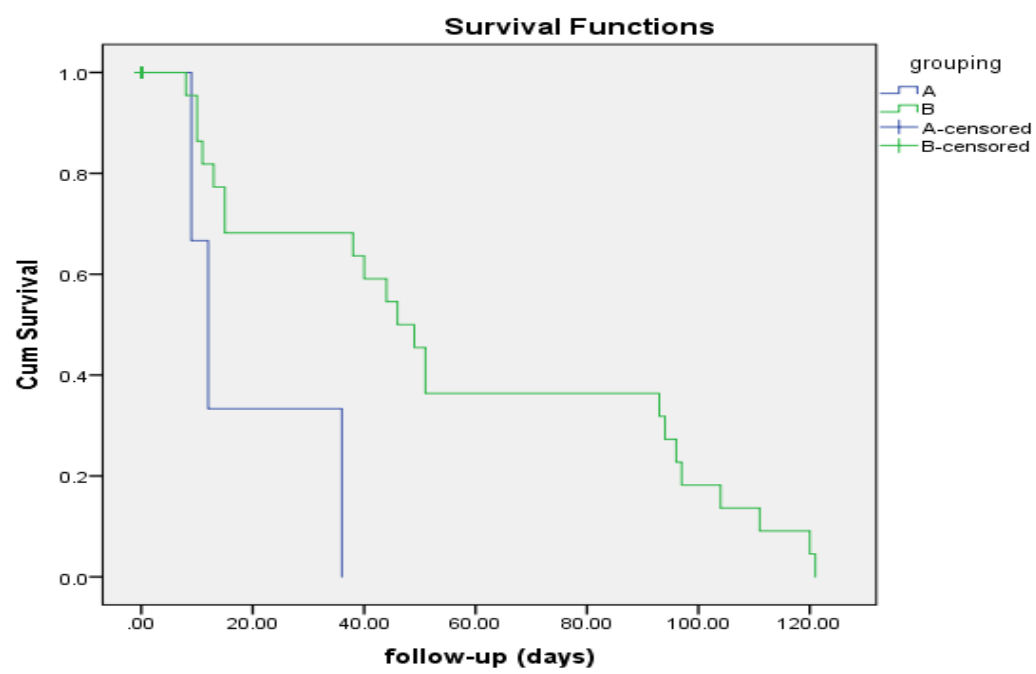

Figure (1): Superficial sternal infection in both groups 


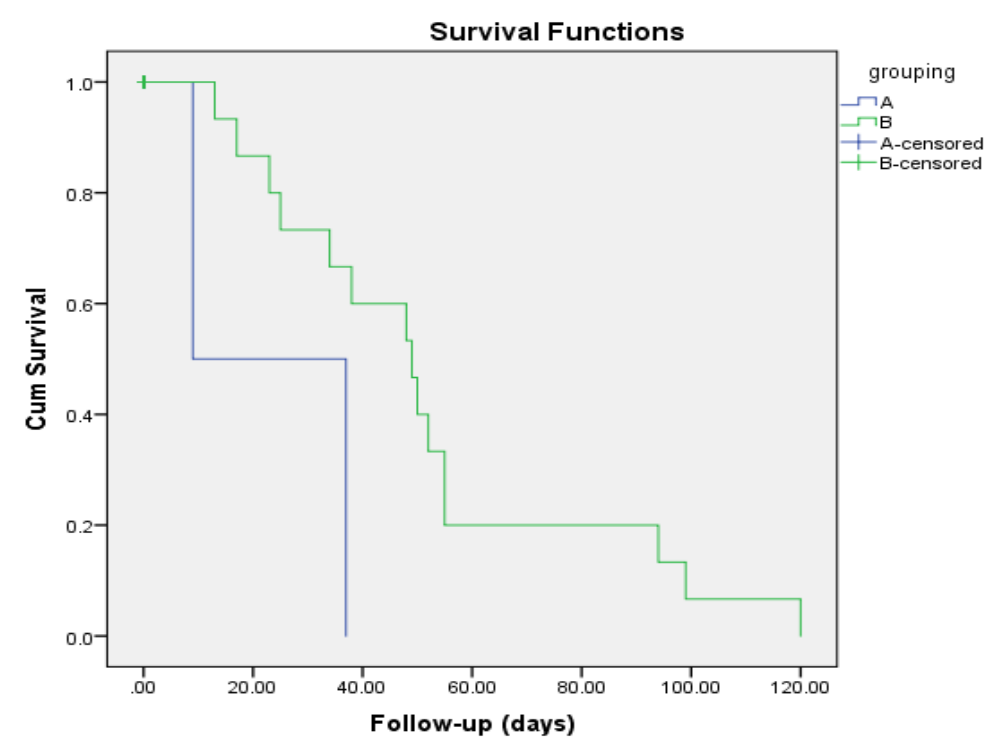

Figure (2): Deep sternal infection in both groups

\section{DISCUSSION}

Our study compared the incidence of superficial and deep sternal wound infections as well as pain severity after use of a PRP in patients who underwent cardiac surgical procedures. Follow-up of postoperative SSWI and DWSI showed that the use of PRP had no adverse reactions in our study. Also, the incidence of superficial and deep sternal wound infection from one month to more than 3 months in group A was reduced. Postoperative pain in group $A$ had a significantly low incidence of moderate and severe pain in the period from one month to more than 3 months.

PRP, an autologous plasma fraction of the peripheral blood, is the easiest regenerative medicine technique that is now increasingly expanding to several medical fields, in particular many surgical specialties (such as plastic surgery, maxillofacial surgery and orthopedic surgery), primarily due to the ease of use and biosafety promoting human communication. [2,8,9].

Several authors have suggested application of PRP before wound closure in cardiac surgery with conflicting findings [1012]. In the early 1990s the autologous PRP was suggested with strong clinical results in the treatment of DSWI [2].
Our results were consistent with the Serraino et al. study, which was conducted on 1093 consecutive patients undergoing cardiac surgery via median sternotomy, and the PRP was administered inside the sternotomy wound prior to closure in a community. They found that regular use of PRP could significantly reduce the incidence of either DSWI or SSWI without any adverse reaction to it [13].

The topical application of platelet gels has been similarly documented in a study by Englert et al. to decrease occurrence of sternal wound infections in patients with cardiac surgery [14].

Khalafi et al. also reported in a retrospective study of a successive series of patients undergoing a coronary artery bypass grafting procedure that platelet-rich injection and platelet-poor plasma significantly reduced incidence of infection of chest wounds [15].

Likewise, PRP's effects on the clinical outcome of patients receiving CABG were studied by Buchwald et al. PRP applied topically to chest and leg wounds appeared to have a beneficial effect on pain, swelling and blood loss [16].

Many publications may clarify the ability of PRP as a prophylactic tool to minimize the postoperative wound complications, in particular the risk of surgical site infection; it 
is suspected that healing following median sternotomy is improved by growth factors released by the PRP. Activated platelets release unique growth factors during the inflammatory process of tissue regeneration, such as transforming growth factors-beta, endothelial vascular growth factor, and the epithelial growth factor. Such factors promote cell proliferation, migration, differentiation and synthesis of matrixes. These same factors can influence the metabolism of chondrocytes, chondrogenesis and enhance bone healing and regeneration [2]. In addition, the most common bacteria responsible for DSWI, Staphylococcus aureus, may be inhibited by the application of PRP [17].

Activated platelet concentrate has been promoted as a potential mode of immune response regulation, with platelet a-granules known to contain a family of cationic peptides which play a significant role in antimicrobial host defense [18].

In contrast to our findings, several studies didn't find that PRP in the sternal wound was associated with infection reduction; Dorge et al. [11] Concluded that the topical application of autologous PRP did not increase the incidence of DSWI in high-risk profile cardiac surgery patients. Regional use of autologous PRP in heart surgery patients with complete sternotomy at high risk for sternal complications did not minimize DSWI incidence.

Only, in patients undergoing cardiac surgery Litmathe et al. found no beneficial effect of PRP on wound healing. It can be argued, however, that a limited number of patients enrolled in both trials may have affected their findings [12].

The present research found that univariate analysis found that older ages, diabetes mellitus, chronic heart disease, and COPD patients were the statistically important risk factors for postoperative sternal wound infection. As with our findings, Garey et al. reported that older patients are at a higher risk of infection with sternal wounds. Older patients needing cardiothoracic surgery appear to have increased risk factors for infection. Many age-related comorbidities increase the susceptibility of a patient to infections, while malnutrition tends to be the main cause of the worse immune function [19].

In some trials, age, COPD, and reoperation represented specific risk factors for SWI. Those variations can be due to disparities in the population [20-22].

Diez et al. have described COPD as an improvement in the risk of wound infection. COPD patients are more vulnerable to tissue hypoxaemia inducing surgical wound infection. Many of these patients require preand/or post-operative corticoid therapy which may facilitate the onset of infection [23].

Additionally, McAlister et al. have reported that diabetes patients are at a higher risk of sternal wound infection relative to other patients [24].

Diabetes has been linked to a higher SWI rate [25]. A broad retrospective study of diabetic patients undergoing cardiac surgery showed that hyperglycemia was an independent risk factor for death, duration of hospital stay, and infection levels and found that a continuous infusion of insulin minimized these risks [26].

In the current study, cultures of the infected sternal wound showed that microorganisms associated with SWI and DSWI were mostly Staphylococcus strains. Similarly, Sjögren et al. Staphylococcus epidermidis was confirmed to be one of the most common agents of poststernotomy mediastinitis; also, about $75 \%$ of Staphylococcus epidermidis strains are methicillin-resistant [27].

Staphylococcus aureus is the other major pathogen in Poststernotomy mediastinitis. The latter microorganism was gradually associated with the colonization of the nares of the patients. National Nosocomial Infection Surveillance System estimates that the MRSA prevalence in ICU patients with nosocomial infections increased from $30 \%$ in 1989 to $60 \%$ in 2005 and that MRSA was the causative microorganism in a third of DSWI patients [28].

\section{CONCLUSION}

In the treatment community, the application of PRP during surgical closure was found to be safe and significantly decreased levels of 
postoperative infection and severity of pain. PRP is a safe, easy, and reproducible therapy that appears to provide both a clinical and a financial benefit for patients undergoing cardiac surgery sternotomy.

\section{Limitations:}

There is a number of limitations to this study including that it is a single-center study, small-sized sample.

Declaration of interest :

The authors report no conflicts of interest. The authors alone are responsible for the content and writing of the paper.

Funding information : None declared

\section{REFERENCES}

1. Sá MP, Silva DO, Lima ÉN, Lima RC, Silva FP, Rueda FG, et al. Postoperative mediastinitis in cardiovascular surgery. Analysis of 1038 consecutive surgeries. Rev Bras Cir Cardiovasc. 2010; 25(1):19-24.

2. Jameson CA. Autologous platelets concentrate for the production of platelet gel. LabMed. 2007; 38:39-42.

3. Eppley BL, Woodell JE, Higgins J. Platelet quantification and growth factor analysis from platelet-rich plasma: implications for wound healing. Plast Reconstr Surg. 2004; 114:15028.

4. Vang SN, Brady CP, Christensen KA, Allen KR, Anderson JE, Isler JR, et al. Autologous platelet gel in coronary artery bypass grafting: effects on surgical wound healing. J Extra Corpor technol. 2007; 39:31-8.

5. Almdahl SM, Veel T, Halvorsen $P$, Vold MB, Mølstad P. Randomizer prospective trial of saphenous vein harvest site infection after wound closure with and without topical application of autologous plateletrich plasma. Eur J Cardiothorac Surg. 2011;39:44-8.

6. Funke F, Reips UD. Why semantic differentials inweb-based research should be made from visual analogue scales and not from 5-point scales. Field Methods. 2012; 24: 310327.

7. Mangram AJ, Horan TC. Pearson ML, Silver LC and Jarvis WR. Guideline for prevention of surgical site infection: Hospital infection control practices advisory committee. Infect Control Hosp Epidemiol 1999; 20: 250-78.

8. Närhi MO, Nordström K. Regulation of cell based therapeutic products intended for human applications in the EU. Reg Med. 2014; 9(3):327-51.

9. Dominijanni A, Cristofaro MG, Brescia A, Giudice M. Platelet gel in oral and maxillofacial surgery: a single-centre experience. Blood Transfus 2012; 2:200-4.

10.Buchwald D, Kaltschmidt C, Haardt H, Laczkovics A, Reber D. Autologous platelet gel fails to show beneficial effects on wound healing after saphenectomy in CABG patients. J Extra Corpor Technol 2008; 3:196-202.

11.DÖrge H, Sellin C, Bury MC, Drescher A, Seipelt R, Grossmann M, et al. Incidence of deep sternal wound infection is not reduced with autologous platelet rich plasma in highrisk cardiac surgery patients. Thorac Cardiovasc Surg. 2013;3:180-4.

12.Litmathe J, Philipp C, Kurt M, Boeken U, Gams E, Feindt $P$. The use of autologous platelet gel (APG) for high-risk patients in cardiac surgery-is it beneficial? Perfusion 2009; 6:381-7.

13.Serraino GF, Dominijanni A, Jiritano F, Rossi M, Cuda A, Caroleo S, et al. Plateletrich plasma inside the sternotomy wound reduces the incidence of sternal wound infections. Int Wound J . 2015; 12:260-264.

14.Englert SJ, Estep TH, Ellis-Stoll CC. Postoperative surgical chest and leg incision sites using platelet gel: a retrospective study. J Extra Corpor Technol. 2008;40:225e228.

15.Khalafi RS, Bradford DW, Wilson MG. Topical application of autologous blood products during surgical closure following a coronary artery bypass graft. Eur $\mathrm{J}$ Cardiothorac Surg. 2008; 2:360-4.

16.Buchwald D, Kaltschmidt C, Haardt H, Laczkovics A, Reber D. Autologous platelet gel fails to show beneficial effects on wound healing after saphenectomy in CABG patients. J Extra Corpor Technol. 2008;3:196-202.

17.Bielecki TM, Gazdzik TS, Arendt J, Szczepanski T, Krol W, Wielkoszynski T. Antibacterial effect of autologous platelet gel enriched with growth factors and other active substances-an in vitro study. J Bone Joint Surg (Br). 2007;7:417-20.

18.Dohan DM, Choukroum J, Diss A, Dohan SL, Dohan AJ, Mouhyi J, et al. Platelet-rich fibrin (PRF): a second-generation platelet concentrate. Part III: A new feature for platelet concentrates? Oral Surg Oral Med Oral Pathol Oral Radiol Endod. 2006; 101: E51-5.

19.Garey KW, Kumar N, Dao T, Tam VH, Gentry LO. Risk factors for postoperative chest wound infections due to Gram-negative bacteria in cardiac surgery patients. $\mathbf{J}$ Chemother. 2006; 18: 4, 402-8.

20.Ariyaratnam $P$, Bland M, Loubani M. Risk factors and mortality associated with deep 
sternal wound infections following coronary bypass surgery with or without concomitant procedures in a UK population: a basis for a new risk model? Interact Cardiovasc Thorac Surg. 2010; 11(5):543-6.

21.Magedanz EH, Bodanese LC, Guaragna JC, Albuquerque LC, Martins V, Minossi SD, et al. Risk score elaboration for mediastinitis after coronary artery bypass grafting. Rev Bras Cir Cardiovasc. 2010; 25(2):154-9.

22.Sá MPBO, Figueira ES, Santos CA, Figueiredo OJ, Lima ROA, Rueda FG, et al. Validation of MagedanzSCORE as a predictor of mediastinitis after coronary artery bypass graft surgery. Rev Bras Cir Cardiovasc. 2011; 26(3):386-92.

23.Diez C, Koch D, Kuss O, Silber R, Friedrich I , Boergermannet J. Risk factors for mediastinitis after cardiac surgery, a retrospective analysis of 1700 patients. J Cardiothorac Surg. 2007; 2: 23.

24. McAlister AF, Man J, Bistritz L, Amad H, Tandon P. Diabetes and coronary artery bypass surgery: an examination of preoperative glycemic control and outcomes. Diabetes Care. 2003; 26: 5, 1518-24.

25.Ledur P, Almeida L, Pellanda LC, Schaan BD. Predictors of infection in post-coronary artery bypass graft surgery. Rev Bras Cir Cardiovasc. 2011; 26(2):190-6.

26. Brown JR, Edwards FH, O'Connor GT, Ross CS, Furnary AP. The diabetic disadvantage: historical outcomes measures in diabetic patients undergoing cardiac surgery the pre-intravenous insulin era. Semin Thorac Cardiovasc Surg. 2006; 18: 281-288.

27.Sjögren J, Malmsjö M, Gustafsson R, Ingemansson R. Poststernotomy mediastinitis: a review of conventional surgical treatments, vacuum-assisted closure therapy and presentation of the Lund University Hospital mediastinitis algorithm. Eur $\mathrm{J}$ Cardiothorac Surg. 2006; 30: 898-905.

28. National Nosocomial Infections Surveillance System. National Nosocomial Infections Surveillance (NNIS) System Report, data summary from January 1992 through June 2004, issued October 2004. Am J Infect Control. 2004; 32: 470- 485.

To Cite This Article:Alanwar M.I., Allam M.M., Helmy K.M. Is Platelet Rich Plasma (PRP) Injection in Sternotomy Wound Better for Healing and Pain Control? Zumj May. 2020(26) No.3,455-464. DOI: 10.21608/zumj.2020.26772.1788. 